\title{
EL DELITO ADUANERO DE CONTRABANDO: IDENTIFICACIÓN DE LOS ELEMENTOS DE SU TIPO PENAL EN COLOMBIA*
}

\author{
Juan José Peña Cuervo** \\ Luisa Fernanda Martínez Espinosa*** \\ Luis Alejandro Peña Cuervo*****
}

Fecha de recepción: 10 de julio de 2017

Fecha de evaluación: 2 de agosto de 2017

Fecha de aprobación: 8 de noviembre de 2017

Artículo de reflexión

DOI: http://dx.doi.org/10.18359/prole.2944

Forma de citación: Peña Cuervo, J. J., Martínez Espinosa, L. F. \& Peña Cuervo, L. A. (2018). El delito aduanero de contrabando: identificación de los elementos de su tipo penal en Colombia. Revista Prolegómenos Derechos y Valores, 21, 41, 131-147+. DOI: http://dx.doi.org/10.18359/prole.2944

\section{RESUMEN}

En este artículo se busca analizar el delito de contrabando en Colombia, que se establece en el artículo 319 de la ley 599/2000 modificado por el artículo 4 de la ley 1762/2015, enfocándose en la conducta que implica y la estructura misma de su tipo penal. Mediante los métodos del análisis y la síntesis se abordan algunos conceptos del derecho de la hacienda pública, derecho tributario, derecho aduanero y derecho penal, para generar un marco teórico que permita comprender la conducta punible de contrabando, debido a la relación constitutiva de este delito con aquellos conceptos y por su configuración como tipo penal en blanco en el Código Penal colombiano.

\section{Palabras clave:}

Contrabando, tipo penal, elementos del tipo, delito aduanero, tributo, derechos de aduana.

* Artículo producto del proyecto de investigación "El delito de contrabando en el Código Penal colombiano", desarrollado en el marco del Semillero de Investigación Eduardo Umaña Palmira de la Universidad Santiago de Cali. El proyecto se ejecutó entre agosto de 2016 y mayo de 2017.

** Abogado y estudiante de maestría en Derecho de la Universidad Santiago de Cali (Cali, Colombia). Integrante del Grupo de Investigación en Ciencia Política, Derecho y Relaciones Internacionales y asistente de la Oficina de Aseguramiento de la Calidad de la misma universidad. Correo electrónico: juanpena@usc.edu.co

*** Doctora en Derecho de la Universidad Externado de Colombia (Bogotá, Colombia). Profesora de dedicación exclusiva, consejera de la Facultad de Derecho y directora del Semillero de Investigación Eduardo Umaña Seccional Palmira de la Universidad Santiago de Cali (Cali, Colombia). Correo electrónico: luisa.martinez00@usc.edu.co

***** Abogado y estudiante de maestría en Derecho de la Universidad Santiago de Cali (Cali, Colombia). Integrante del Semillero de Investigación Eduardo Umaña Seccional Palmira y asesor del consultorio jurídico de la misma universidad. Correo electrónico: consultoriojuridicopalmira01@usc.edu.co 


\section{THE CUSTOM FELONY OF SMUGGLING: IDENTIFYING ITS CRIMINAL ELEMENTS IN COLOMBIA}

\section{SUMMARY}

This article pursues to analyze the smuggling felony in Colombia (which is stablished by the article 319, law 533/2000, modified by the article 4, law 1762/2015) focusing in the intended behavior and the structure of its criminal type. Through both the analysis and synthesis methods public finances, tax law, customs law and criminal law concepts are approached in order to generate a theoretical framework to understand the smuggling felony as a punishable conduct. This is the result of this felony essential relationship with the aforementioned concepts and its nature as criminal law in blank in the Colombian Criminal Code.

\section{Keywords:}

Smuggling, elements of a crime, custom offense, tribute, customs rights.

\section{O CRIME ADUANEIRO DE CONTRABANDO: IDENTIFICAÇÃO DOS ELEMENTOS DO SEU TIPO CRIMINAL NA COLÔMBIA}

\section{RESUMO}

Neste artigo procura-se analisar o crime de contrabando na Colômbia, que se estabelece no artigo 319 da Lei 599/2000, modificada pelo artigo 4 da Lei 1762/2015, com foco na conduta que implica e na própria estrutura de seu tipo criminal. Através dos métodos de análise e a síntese são abordados alguns conceitos da lei das finanças públicas, do direito tributário, do direito aduaneiro e do direito penal, para gerar um quadro teórico que permita compreender a conduta punível do contrabando, devido à relação constitutiva deste crime com esses conceitos e por sua configuração de tipo criminoso em branco no Código Penal colombiano.

\section{Palavras chave:}

Contrabando, tipo criminal, elementos do tipo, crime alfandegário, tributo, direitos aduaneiros.

\section{Introducción}

El contrabando es un delito cuyo análisis supone adentrarse tanto en el derecho penal como en las normas del derecho de la hacienda pública, el derecho tributario y el derecho aduanero, debido a que al ser un tipo penal en blanco su "supuesto de hecho se encuentra desarrollado total o parcialmente por una norma de carácter extrapenal" (Corte Constitucional, Sentencia C-121/2012). Por esta razón, existen conceptos básicos de estas áreas del derecho que se encuentran en normas jurídicas y que contribuyen a dar claridad sobre lo que connotan los elementos del tipo penal de este delito, como son: gasto público, ingreso público, tributos, obligación tributaria, hecho imponible, contribución, derechos de aduana, territorio aduanero, importación, exportación, entre otros. De modo que, el desconocimiento de estos conceptos conlleva problemas semánticos al momento de interpretar y aplicar este tipo penal, además que ello impide saber lo que es el contrabando y las implicaciones de su comisión para la sociedad. 
Así las cosas, el objetivo principal de este artículo es analizar el delito de contrabando, que determina el artículo 319 de la ley 599/2000 modificado por el artículo 4 de la ley 1762/2015, en relación con la conducta que comporta y la estructura misma de su tipo penal. En cuanto a la metodología, se trata de una investigación básica por cuanto se da prioridad a la sistematización de conceptos jurídicos del tema objeto de investigación con sustento en la doctrina y la jurisprudencia. El tipo de estudio es descriptivoexplicativo, el método es el análisis y la síntesis, pues se identifican y delinean los elementos del tipo penal del contrabando y se evidencia teóricamente su nexo con los conceptos aludidos. En tal sentido, este artículo científico contribuye a esclarecer el tema para los operadores judiciales, abogados y personas en general sobre la adecuación típica del actuar de los procesados con esta norma penal.

Para lograr este fin se propone una noción de contrabando desde un enfoque que abarca el derecho penal, el derecho de la hacienda pública, el derecho tributario y el derecho aduanero; $y$ se descompone el tipo penal del contrabando establecido en el artículo 319 de la ley 599/2000 modificado por el artículo 4 de la ley 1762/2015, para señalar cada uno de sus elementos. Por último se exponen las conclusiones.

\section{A. Noción de contrabando}

Ferreira (2006) explica que etimológicamente la palabra contrabando es de raíz hispánica y se compone por la preposición 'contra': en contra de y por el sustantivo 'bando': ley, disposición gubernamental o bando; pues esta palabra se generó inicialmente para significar la producción y el comercio de mercancías que se realizaban en contra de las leyes emitidas por el Estado.

Sin embargo, con el tiempo el sentido de la palabra contrabando ha dejado tal generalidad y ha pasado a significar el delito "que consiste en introducir al país o exportar de él productos o mercancías gravados por impuestos, sin satisfacer íntegramente esta exigencia [...]" (Indriago,
1976, p. 2). Con base en la anterior definición y para una mayor precisión en el contexto colombiano, se puede afirmar por el momento que el contrabando es un delito que consiste en la introducción y extracción del territorio aduanero nacional de mercancías sin el pago de los derechos de aduana.

Los derechos de aduana o aranceles aduaneros son impuestos, considerados por la doctrina como una clase de tributo (López, 2014), que tienen las siguientes funciones según la Corte Constitucional:

Los autores coinciden en destacar el doble carácter o función de estos impuestos: fiscal (instrumento de recaudo público) y económico (instrumento de desarrollo y estabilidad económicas). Estos dos elementos normalmente van unidos y dependiendo de la época histórica uno ha prevalecido sobre el otro. Por el aspecto fiscal el impuesto de aduanas provee ingresos fiscales al Estado y obra en su exclusivo beneficio. Por el aspecto económico, el impuesto de aduanas, no se utiliza como fuente de exacción fiscal sino como instrumento de políticas orientadas a favorecer la producción nacional (gracias a su capacidad para discriminar mediante la manipulación de la tarifa y el régimen entre la producción nacional y la extranjera) y promover la estabilidad económica (el aumento o disminución de los aranceles, la contracción o ampliación de las importaciones, pueden afectar el nivel general de precios y los movimientos de la oferta y la demanda) (Sentencia C-510/1992).

De esta manera, la primera función de los derechos de aduana consiste en lo recaudado a favor de los ingresos públicos, mientras que la segunda función es extrafiscal, ya que el impuesto de aduanas sirve también para exteriorizar la política económica del Estado, la cual representa todas aquellas decisiones estatales encaminadas a intervenir en la economía nacional y conducirla para lograr unos resultados determinados, como la disminución del desempleo, proteger e incentivar la producción nacional, buscar la estabilidad económica y en últimas alcanzar un 
orden económico y social justo en pro de todas las personas.

El fundamento de lo anterior se encuentra en que el Estado colombiano tiene el deber de realizar las acciones pertinentes para conseguir el bienestar de las personas y la sociedad (Ramírez, 1998). Colombia al ser un Estado social de derecho según el artículo 1 constitucional y de acuerdo con las Sentencias T-533/1992 y SU-747/1998 de la Corte Constitucional, además de garantizar formalmente los derechos de los ciudadanos debe cumplir con unos fines en la sociedad mediante su intervención en ella para la materialización de esos derechos. Incluso, el artículo 2 de la Carta Política establece que:

Son fines esenciales del Estado: servir a la comunidad, promover la prosperidad general y garantizar la efectividad de los principios, derechos y deberes consagrados en la Constitución; facilitar la participación de todos en las decisiones que los afectan y en la vida económica, política, administrativa y cultural de la Nación; defender la independencia nacional, mantener la integridad territorial y asegurar la convivencia pacífica y la vigencia de un orden justo.

El gasto público es un instrumento importante que tiene el Estado para llevar a cabo un orden económico y social, impulsar el crecimiento económico y ejecutar sus demás fines (Chávez, 2000). El gasto público es "la inversión de los ingresos de las entidades públicas en la satisfacción de las necesidades colectivas" (García y Ortega, 2004, p. 50), lo cual incide directamente en la materialización de los derechos constitucionalmente reconocidos. No obstante, no todo gasto público se realiza en servicios que se prestan a la comunidad que representan una inversión al mejorar la calidad de vida de los individuos y la fuerza productiva de la sociedad -como educación, salud, obra pública, vivienda, entre otros-, sino que también este gasto se hace para suplir los costos de funcionamiento del Estado y el pago de la deuda pública ${ }^{1}$.

1 La deuda pública se adquiere de diversas maneras, por ejemplo, cuando el Estado hace emisión de los títulos valores denominados bonos para que los agencien los
Entonces, si el ingreso público es el recaudo de aquello útil y necesario para el funcionamiento y cumplimiento de los fines del Estado, su relación con el gasto público deviene de la idea de que de todo deber nace un derecho, es decir que, si el Estado debe garantizar tanto su existencia como la prestación de servicios a favor de los derechos de las personas, tiene el derecho de abastecerse de medios pecuniarios indispensables para adelantar tales tareas (Carrara, 1982).

Así pues, una de las principales fuentes de ingresos públicos son los tributos, definidos como prestaciones pecuniarias a favor del Estado que se decretan por la ley en desarrollo de los siguientes principios del derecho de la hacienda pública: (i) principio de solidaridad: el dinero que será destinado a la inversión en la sociedad a través del gasto público puede tener como origen el sector privado, pues todos los sujetos tienen el deber moral y legal de contribuir a la satisfacción de las necesidades de la comunidad y a la existencia misma del Estado; y (ii) principio de reserva de ley: los tributos solo pueden imponerse mediante normas jurídicas aprobadas por un órgano de representación popular respetando el derecho de propiedad de las personas (García y Ortega, 2004; Plazas, 2005).

Sobre este último principio, el término ley debe entenderse en este contexto en un sentido material y no formal, pues no solo se refiere a las normas expedidas por el Congreso de la República de Colombia llamadas de tal forma, sino que igualmente comprende los actos administrativos de carácter general, las ordenanzas que expiden las asambleas departamentales y los acuerdos emitidos por los concejos municipales, así como los decretos del presidente de la República que establecen los tributos denominados derechos de aduana. Por esta razón, los tributos son expresión de la soberanía, de la cual es titular el pueblo de acuerdo con el artículo 3 de la Constitución Política, que es ejercida directamente o a través

individuos en calidad de acreedores, o también cuando al Estado le es otorgado un crédito por otro Estado u órgano internacional como el Fondo Monetario Internacional, etc. 
de sus representantes como lo son aquellos servidores públicos que conforman los órganos estatales antes mencionados (Amatucci y González, 2001; Plazas, 2005).

Los fundamentos constitucionales de los tributos son el artículo 58 que expresa que "La propiedad es una función social que implica obligaciones [...]", y el artículo 95 numeral 9 al instaurar que son deberes de todo ciudadano "Contribuir al financiamiento de los gastos e inversiones del Estado dentro de conceptos de justicia y equidad". La Corte Constitucional en Sentencia C-040/1993 afirma que en esta última norma constitucional "el término 'contribuir' se usa [para] entenderse en el sentido más corriente menos técnico posible, pues se refiere, al acto material de aportar dinero, cualquiera que sea la categoría u origen de la obligación [...]", dando pie para que la Corte proponga que la palabra tributo es genérica y engloba: tasas, contribuciones especiales e impuestos. Al respecto, Plazas (2005) asegura que se crea la tricotomía de los tributos en el derecho de la hacienda pública en Colombia mediante la sentencia anterior.

Cuando las normas jurídicas determinan tributos, de ellos devienen obligaciones para las personas, cuyo cumplimiento es una de las formas en que efectúan sus deberes como ciudadanos. Estas obligaciones tributarias las caracteriza la Corte Constitucional como vínculos jurídicos entre las personas y el Estado que contienen los siguientes elementos:

[...] 1) el sujeto activo o acreedor, que es el Estado, el cual se concreta y particulariza a través de los correspondientes órganos y dependencias del orden nacional y territorial. 2) el sujeto pasivo o deudor, constituido por los contribuyentes y los no contribuyentes, sean personas naturales, jurídicas, sociedades, o asimiladas. 3) el objeto u obligación que consiste en dar, hacer y no hacer. Es decir, dar: en cuanto el sujeto pasivo tiene que pagar el valor del impuesto a cargo en efectivo, con títulos valores $\mathrm{u}$ otros medios económicamente idóneos; hacer: que se traduce en una serie de actos positivos, tales como declarar, retener en la fuente, certificar esa retención, e informar en los casos y condiciones que la Administración Tributaria exija con arreglo a la Constitución y la ley. Conductas que por otra parte explican el hecho de que los no contribuyentes sean considerados sujetos pasivos de la obligación fiscal, pues según se aprecia, el carácter de sujeto pasivo no es exclusivo de quienes están obligados a pagar. Antes bien, el simple llamado o invitación a un no contribuyente para que rinda legalmente cierta información ante la Administración Tributaria, lo hace sin más sujeto pasivo de la obligación tributaria; no hacer, que implica una abstención, entendida esta como la prohibición legal de evadir o eludir el tributo. 4) la causa, que es de dos naturalezas, a saber: causa remota, o sea la ley misma, por cuanto no puede haber tributo sin ley previa que lo establezca; causa inmediata, o sea el hecho económico, también conocido como hecho generador o hecho imponible (Sentencia C-711/2001).

Este último elemento, la causa inmediata o hecho generador, se define como el presupuesto que tiene la norma tributaria que al realizarse nace la obligación para el sujeto pasivo, aunque para el cumplimiento de esta obligación se debe cuantificar si consiste en una prestación de dar, pues si el tributo es fijo, la misma norma tributaria instituye la cantidad que siempre se debe pagar, pero si el tributo es variable la norma establece es la base gravable y la tasa, que aplicándose la tasa a la base gravable se determina el monto que debe pagar el contribuyente.

La base gravable se determina gracias al hecho imponible y conceptualmente es la dimensión o magnitud del objeto gravado ${ }^{2}$ por la norma tributaria, por ello se expresa en medidas de moneda, de peso, de volumen, de longitud, etc., mientras que la tasa es el índice o porcentaje sobre la base gravable que tiene el Estado derecho a

El objeto gravado o el objeto del tributo es aquel sobre el cual el Estado ha impuesto una carga o contribución. 
cobrar al sujeto pasivo de la obligación tributaria (Ferreiro, 2001; Russo, 2001).

Aplicado lo anterior a los derechos de aduana, su hecho imponible es la importación ${ }^{3}$ al territorio aduanero colombiano de mercancías para consumo ${ }^{4}$, aunque excepcionalmente $e^{5}$ también se pueden generar por la exportación ${ }^{6}$ de estas; la base gravable de estos impuestos es el valor de las mercancías, que se obtiene mediante procedimientos de valorización establecidos en el Acuerdo Relativo a la Aplicación del Artículo VII del Acuerdo General sobre Aranceles Aduaneros y Comercio de 1994 -Código de Valorización de la Organización Mundial del Comercio-, aprobado en Colombia con la ley 170/1994.

La tasa de los derechos de aduana son los porcentajes fijados en el decreto 4927/20117 -Arancel de Aduanas-, que el Estado tiene derecho a cobrar; el sujeto activo o acreedor de los derechos aduaneros es la Unidad Administrativa Especial, Dirección de Impuestos y Aduanas Nacionales ${ }^{8}$

3 La importación consiste en la introducción de mercancías provenientes de otros territorios aduaneros al territorio aduanero colombiano cumpliendo las exigencias que la ley impone.

4 El consumo de la mercancía connota tanto su uso o utilización como su consumo propiamente dicho, ya sea total o parcialmente.

5 Gravar la exportación es excepcional porque es una desventaja para la mercancía sobre la que recaen los derechos de aduana, pues su precio aumenta y cuando se oferte en un territorio aduanero extranjero tendrá un precio más alto frente a las mercancías de la misma especie que se encuentran allí, lo cual es un evento no querido ni por el comerciante exportador ni por el Estado, ya que va en contra de la producción nacional y del fortalecimiento de su economía, por ello se grava la exportación solo cuando la mercancía no tiene la anterior afectación o cuando el Estado busca que cierta mercancía no abandone el territorio aduanero nacional.

6 La exportación consiste en la salida de mercancías del territorio aduanero colombiano hacia otros territorios aduaneros cumpliendo las exigencias que la ley impone.

7 El Arancel de Aduanas compila las mercancías sobre las que recaen los derechos de aduana, allí se organizan por categorías y se encuentra expresamente la tasa de cada mercancía.

8 La autoridad aduanera o aduana en Colombia son los servidores públicos que pertenecen a la Dirección de Impuestos y Aduanas Nacionales, que como entidad estatal se encarga de exigir el cumplimiento del conjunto según el numeral 1 del artículo 33 del decreto 390/2016 - estatuto aduanero colombiano vigente-, mientras que el sujeto pasivo o deudor de estos impuestos según el mismo artículo 33 es el importador, el exportador, los declarantes de un régimen aduanero, los operadores de comercio exterior y toda persona que en desarrollo de su actividad haya intervenido de manera indirecta en el cumplimiento de cualquier formalidad, trámite u operación aduanera; y la causa remota se refiere al conjunto de normas jurídicas que regulan los derechos de aduana en Colombia, como son la ley 7/1991, la ley 170/1994, el decreto 4927/2011, la ley 1609/2013-ley marco de aduanas-y el decreto 390/2016 (Pardo, 2009).

Por lo que, el contrabando es un delito aduanero en razón a que su comisión conlleva el incumplimiento de obligaciones jurídicas, tales como: (i) no se realiza una obligación que se tiene como contribuyente cuya prestación es de dar o pagar los derechos de aduana; (ii) el incumplimiento de una obligación de hacer, que consiste en rendir información cierta a la aduana para que esta lleve a cabo efectivamente su función de control de las mercancías que entran y salen del territorio aduanero colombiano; y (iii) el incumplimiento de una obligación de prestación de no hacer, que es la de abstenerse de realizar la introducción o extracción del territorio aduanero colombiano de mercancías por zona secundaria aduanera, es decir, por un lugar que no está habilitado por la aduana para ejercer tales actividades.

Con base en todo lo anterior, se comprende que el contrabandista se apropia de la contribución que el Estado tiene derecho a recibir y que este podría usar, ya sea para suplir los gastos de su funcionamiento o para la prestación de los derechos constitucionalmente reconocidos mediante los distintos servicios públicos que brinda a las personas. Pero además, el contra-

de las normas jurídicas de carácter tributario y aduanero, implicando ello que debe controlar la introducción y extracción de mercancías del territorio aduanero, verificar si las mercancías que están siendo transportadas no están prohibidas por razones de salud o seguridad pública, cobrar los impuestos aduaneros, entre otras funciones. 
bando no permite que se materialice la función extrafiscal de los derechos de aduana por ir en contra de los resultados económicos que busca el Estado con su política económica, pues este delito incrementa el desempleo y deteriora la producción nacional en detrimento del orden económico y social, debido a que el no pago de derechos de aduana acarrea que las mercancías contrabandeadas tengan precios más bajos al competir con otras en el territorio aduanero colombiano y sean por ello preferidas por los consumidores, produciendo esto una disminución en los ingresos de las empresas nacionales que sí pagan su contribuciones y ejecutan sus actividades comerciales en el marco legal, viéndose estas en la necesidad de reducir el número de sus trabajadores o incluso dejar de operar por insolvencia. Por lo que "el contrabando es una manera sucia de ganar dinero y altamente perjudicial para el país" (Ferreira, 2006, p. 58).

En el Estado colombiano, el contrabando ha sido un flagelo que "ha existido durante décadas, incluso en algunas regiones fronterizas hace parte de la cotidianidad de la población, puesto que se dedican a intercambiar productos con los países vecinos, en ocasiones con el mismo apoyo de las autoridades" (Muñoz, 2015, p. 8).

La Corte Constitucional expresa sobre este tema, conociendo de una demanda de inconstitucionalidad en contra del artículo 319 de la ley 599/2000 modificado por el artículo 4 de la ley $1762 / 2015$, que

El contrabando, desarrollado a gran escala, afecta gravemente al aparato productivo colombiano, en la medida en que los industriales y agricultores deben entrar a competir en condiciones de marcada desventaja, dado que sus productos deben ser vendidos a un mayor precio, debido a la respectiva carga tributaria asumida.

El impacto fiscal de las empresas que compiten legalmente es la reducción de la participación en el mercado, la disminución de sus utilidades, la pérdida de empleos, entre otros.
Al mismo tiempo, el contrabando afecta gravemente las finanzas del Estado colombiano en dos niveles: nacional y departamental. La Nación deja de percibir importantes recursos, que deberían entrar a sus arcas, debido al pago de aranceles, impuesto de valor agregado y renta. A su vez, las entidades territoriales no recaudan recursos muy significativos, en especial, en productos tales como cigarrillos y licores, faltantes que terminan afectando el disfrute de derechos económicos, sociales y culturales (Sentencia C-203/2016).

Sin embargo, cabe señalar que existen zonas de régimen especial aduanero que generan flexibilización de las normas jurídicas sobre importación y exportación, pues estas zonas son "áreas delimitadas, que para efectos aduaneros no se entienden parte del territorio nacional, dado que en ellas se aplican beneficios aduaneros y tributarios especiales con relación a operaciones que se realizan en el territorio nacional" (Naranjo y Zapata, 2012, p. 8). Este tipo de zonas las regula en Colombia el decreto 390/2016 y son: (i) Puerto libre de San Andrés, Providencia y Santa Catalina; (ii) Urabá, Tumaco, Guapi, Leticia, Inírida, Puerto Carreño, La Primavera y Cumaribo; y (iii) Maicao, Uribia y Manaure.

La finalidad de las zonas de régimen especial aduanero es promover el comercio de mercancías para generar ciertos estímulos de desarrollo cultural, económico y social en esos territorios, siempre que dichas mercancías se consuman en su interior. Sobre el particular, Naranjo y Zapata (2012) agregan que

El propósito de las zonas de régimen especial aduanero es incentivar la inversión de las empresas tanto nacionales como extranjeras, brindándoles y garantizándoles unos beneficios especiales, lo cual hace más atractiva la inversión, dichas zonas se encuentran apartadas de la grandes ciudades y por lo general no cuentan con una gran infraestructura, pero a su vez por estar ubicadas en lugares estratégicos de nuestro país presentan una gran oportunidad de ser competitivos a la hora de entrar en la globalización de los mercados, el 
gobierno con el fin de lograr que las grandes empresas realicen la inversión en cada una de estas zonas, ofrece incentivos y beneficios a cambio de que garanticen empleo para la población y así poder dinamizar la economía y hacer un gran trabajo en la parte social, esta estrategia usada por el gobierno que opera hoy en día no ha dado los resultados esperados debido a que la utilización de estas zonas no ha alcanzado la meta establecida inicialmente y los habitantes de cada una de estas poblaciones no se están viendo beneficiados con la puesta en marcha de estas zonas (p. 10).

La forma en que se introducen y extraen mercancías de estas zonas la regula el mismo decreto 390/2016, en específico sus títulos XII y XIII, por lo que si se desea saber si se genera importación, exportación o contrabando en un caso concreto que involucra una zona de régimen especial aduanero, deben verse las particularidades de esa zona y el tipo de mercancía que se trata. Se precisa que no se hará un estudio detallado de las zonas de régimen especial aduanero en este artículo científico por cuestiones de extensión y por no ser el objeto de análisis, siendo incluso un tema que merece una investigación independiente.

\section{Tipología de contrabando}

La palabra tipología alude a las clases de contrabando que se establecen en la ley penal. El delito de contrabando se encuentra tipificado en Colombia en el artículo 319 de la ley 599/2000 modificado por el artículo 4 de la ley 1762/2015, siendo los dos primeros incisos de este artículo los siguientes:

El que introduzca o extraiga mercancías en cuantía superior a cincuenta (50) salarios mínimos legales mensuales, al o desde el territorio colombiano por lugares no habilitados de acuerdo con la normativa aduanera vigente, incurrirá en prisión de cuatro (4) a ocho (8) años y multa del doscientos $(200 \%)$ al trescientos (300\%) por ciento del valor aduanero de los bienes objeto del delito.
En [sic] que oculte, disimule o sustraiga de la intervención y control aduanero mercancías en cuantía superior a cincuenta (50) salarios mínimos legales mensuales, o las ingrese a zona primaria definida en la normativa aduanera vigente sin el cumplimiento de las formalidades exigidas en la regulación aduanera, incurrirá en la misma pena de prisión y multa descrita en el inciso anterior.

Analizando los incisos anteriores y con base en lo expuesto en el documento Tipologías de lavado de activos relacionadas con contrabando elaborado por la Dirección de Impuestos y Aduanas Nacionales y la Unidad de Información y Análisis Financiero (2006), se puede afirmar que en Colombia existen dos clases de contrabando, ya que el primer inciso del artículo antes citado establece el contrabando abierto y el segundo inciso de este el contrabando técnico.

Luego, el contrabando abierto es la introducción o extracción de mercancías gravadas por el Estado a través de lugares no habilitados por la autoridad aduanera -es decir, a través de zona secundaria aduanera-, eludiendo de esta forma a la aduana y haciendo que esta no realice su función de control sobre tales mercancías.

Por su parte, el contrabando técnico consiste en introducir o extraer del territorio aduanero colombiano mercancías gravadas por el Estado a través de lugares habilitados para ello por la autoridad aduanera -esto es, a través de zonas primarias aduaneras-, ya sea ocultando las mercancías para que no sean vistas por la aduana, disimulándolas entre otras cuando se estén inspeccionando o sustrayéndolas de los lugares en que se almacenan después de su decomiso, pero en cualquier caso buscando que la autoridad aduanera no realice a cabalidad su función de control sobre las mercancías. Al respecto, Carantón (2016) asevera que

Se puede evidenciar que la evasión de controles e impuestos por parte de los criminales, encuentran la manera de cometer sus ilícitos simulando algo de "legalidad" en sus operaciones para no ser detectados fácilmente, es 
importante notar que este tipo de prácticas van acompañadas de la complicidad muchas veces de otros intermediarios de las operaciones de comercio que resultan ser facilitadores de este delito (p. 14).

\section{B. El tipo penal de contrabando en Colombia}

El tipo penal es un mecanismo legal que sirve para determinar, describir, calificar, hacer conocer y prohibir los comportamientos que el legislador considera como delito, implicando que se dé con preexistencia legal la definición inequívoca de la conducta humana amenazada con pena (Gómez, 2005).

Ahora bien, el contenido del tipo penal consta de: (i) un tipo subjetivo que comprende la parte interna de la descripción típica; y (ii) un tipo objetivo que comprende el núcleo real u objetivo de todo delito, abarcando lo que debe existir del tipo penal en el mundo externo (Welzel, 1956, 2004).

Así las cosas, el tipo subjetivo está compuesto por alguna de las modalidades de la conducta punible, que según el artículo 21 de la ley 599/2000 -Código Penal colombiano- son el dolo, la culpa y la preterintención, definidos en la misma ley así:

Artículo 22. Dolo. La conducta es dolosa cuando el agente conoce los hechos constitutivos de la infracción penal y quiere su realización. También será dolosa la conducta cuando la realización de la infracción penal ha sido prevista como probable y su no producción se deja librada al azar.

Artículo 23. Culpa. La conducta es culposa cuando el resultado típico es producto de la infracción al deber objetivo de cuidado y el agente debió haberlo previsto por ser previsible, o habiéndolo previsto, confió en poder evitarlo.

Artículo 24. La conducta es preterintencional cuando su resultado, siendo previsible, excede la intención del agente.
Pero, el tipo subjetivo está compuesto también en ocasiones por los elementos subjetivos, los cuales son los propósitos, intenciones, motivos o impulsos del sujeto activo en la comisión del delito que se encuentran descritos en algunos tipos penales (Velásquez, 2004).

Por otra parte, el tipo objetivo se estructura con los elementos básicos que son: (i) los sujetos activo y pasivo, el primero de estos es el individuo que lleva a cabo la conducta descrita en el tipo penal y el sujeto pasivo es el titular del bien jurídico protegido en el caso concreto -la persona, el Estado o el conglomerado social-, pudiéndose clasificar ambas clases de sujetos, siempre que sean personas por su número en singular o plural, según se trate de una o más de una persona, como también clasificarse en sujetos indeterminados y calificados, según pueda cualquiera ocupar tal papel o requiera unas calidades especiales para ello; (ii) la conducta humana, que se refiere a la acción u omisión que describe el tipo penal, pues el legislador valiéndose de un verbo rector realiza la concreción de lo prohibido, aunque en ocasiones hace uso de verbos accesorios al verbo rector para lograr una mayor descripción y precisión; (iii) el resultado, que se entiende como el efecto o la consecuencia de la conducta en el mundo, pudiéndose encontrar en el plano físico como en el psicológico; (iv) el objeto de la acción, el cual es todo aquello sobre lo que se materializa la afectación al bien jurídico tutelado y hacia lo que el sujeto activo orienta su comportamiento en el mundo; y (v) el bien jurídico, que es un concepto abstracto entendido como aquello que el tipo penal protege (Velásquez, 2004).

Sobre el bien jurídico, Fernández (1989) afirma que su protección es la razón o finalidad del tipo penal, pues no puede el legislador prohibir o sancionar conductas humanas sin motivo alguno, sino que lo debe hacer para otorgar protección a los bienes más importantes del individuo y la sociedad, constituyéndose el bien jurídico en el objeto jurídico del delito.

Ahora bien, se debe agregar que el tipo objetivo tiene en ocasiones elementos aleatorios o 
accidentales, presentándose estos solo en algunos tipos penales: (i) los elementos descriptivos, que realizan una mayor caracterización de la conducta humana en cuanto al modo, tiempo y lugar de su ocurrencia; (ii) los elementos normativos, que se refieren a todos aquellos términos que remiten a otras normas jurídicas u otro campo del conocimiento humano para su interpretación; y (iii) las circunstancias agravantes y atenuantes de la responsabilidad de carácter genérico y concreto, que aunque la mayoría estén establecidas en los artículos 55 al 58 de la ley 599/2000, pueden también a veces estar específicamente en el tipo penal y ser verdaderos elementos de este (Gómez, 2005; Velásquez, 2004).

Con base en lo anterior, se procederá ahora a señalar los elementos del tipo penal del contrabando, el cual como ya se indicó, se consigna en el artículo 319 de la ley 599/2000 modificado por el artículo 4 de la ley 1762/2015, establecido de la siguiente manera:

Artículo 319. Contrabando. El que introduzca o extraiga mercancías en cuantía superior a cincuenta (50) salarios mínimos legales mensuales, al o desde el territorio colombiano por lugares no habilitados de acuerdo con la normativa aduanera vigente, incurrirá en prisión de cuatro (4) a ocho (8) años y multa del doscientos (200\%) al trescientos (300\%) por ciento del valor aduanero de los bienes objeto del delito.

En [sic] que oculte, disimule o sustraiga de la intervención y control aduanero mercancías en cuantía superior a cincuenta (50) salarios mínimos legales mensuales, o las ingrese a zona primaria definida en la normativa aduanera vigente sin el cumplimiento de las formalidades exigidas en la regulación aduanera, incurrirá en la misma pena de prisión y multa descrita en el inciso anterior.

Si las conductas descritas en los incisos anteriores recaen sobre mercancías en cuantía superior a doscientos (200) salarios mínimos legales mensuales, se impondrá una pena de nueve (9) a doce (12) años de prisión y multa del doscientos
(200\%) al trescientos (300\%) por ciento del valor aduanero de los bienes objeto del delito.

Se tomará como circunstancias de agravación punitiva, que el sujeto activo tenga la calidad de Usuario Altamente Exportador (Altex), de un Usuario Aduanero Permanente (UAP), o de un Usuario u Operador de Confianza, de un Operador Económico Autorizado (OEA) o de cualquier operador con un régimen especial de acuerdo con la normativa aduanera vigente. Asimismo será causal de mayor punibilidad la reincidencia del sujeto activo de la conducta.

Parágrafo. La legalización de las mercancías no extingue la acción penal.

\section{El tipo subjetivo del tipo penal de contrabando}

De acuerdo con el artículo 21 de la ley 599/2000, las modalidades de la conducta punible de la culpa y la preterintención son castigadas solo cuando la ley penal expresamente lo señale, implicando que por regla general los tipos penales son dolosos. Entonces, al no haber en el tipo penal del contrabando indicación alguna de las modalidades de la culpa o preterintención, significa que este delito se agota únicamente mediante dolo.

En cuanto a los elementos subjetivos, no hay ninguno en el tipo penal del contrabando al no haber ninguna descripción de propósitos, intenciones, motivos o impulsos del sujeto activo en la comisión del delito.

\section{El tipo objetivo del tipo penal de contrabando}

El sujeto activo del tipo penal del contrabando es singular $e$ indeterminado, pues tanto en el inciso 1 -contrabando abierto- como en el inciso 2 -contrabando técnico- se establece "El que", para significar que cualquier persona individual puede cometer contrabando abierto y técnico. Sin embargo, en el segundo inciso en realidad se indica es "En [sic] que", sobre lo cual 
se puede afirmar que es un error de redacción que se cometió en alguna etapa del proceso de elaboración y sanción de la ley 1762/2015, siendo evidente que la voluntad del legislador colombiano consistió en tipificar "El que".

Por su parte, el sujeto pasivo de este delito es el Estado y el conglomerado social, pues por una parte la comisión de este delito implica el no pago de derechos de aduana que conlleva un menoscabo para los ingresos públicos y que no se permita realizar el control de aduana adecuadamente, pero además comporta una vulneración a la sociedad que se refleja en la calidad de vida y el bienestar de todas las personas.

Sobre la conducta del tipo penal del contrabando, se identifican los verbos rectores en el inciso 1 -contrabando abierto- de: (i) "introduzca": verbo que significa entrar una cosa a un lugar; y (ii) "extraiga": verbo que significa sacar una cosa de un lugar. Pero también en el inciso 2 -contrabando técnico- son verbos rectores: (i) "oculte": verbo que significa esconder una cosa en otra; (ii) "disimule": verbo que significa camuflar, disfrazar o hacer pasar una cosa por otra; (iii) "sustraiga": verbo que significa quitar el dominio de alguien una cosa; y (iv) "ingrese": al igual que introducir, verbo que significa entrar una cosa a un lugar. Implicando lo anterior que el delito de contrabando es de acción y alternativo, debido a que sus verbos rectores significan que el sujeto activo debe hacer un algo positivo en el mundo exterior y puede cometerse contrabando realizando uno solo de estos. Además, no hay verbos accesorios en el tipo penal del contrabando.

Sobre esos verbos rectores del tipo penal del contrabando, la Corte Constitucional afirma que:

[...] no son ingredientes normativos del tipo, en cuanto no existe una norma constitucional, legal o administrativa que precise el sentido de dichas expresiones. Se trata de formas verbales cuya interpretación debe ser la usual a partir de la búsqueda de su semántica. Esto cumple la función de límite a la libertad, en cuanto se trata de expresiones corrientes, accesibles a la comprensión de todas las personas y no solamente del juez, lo que permite que las personas tengan conciencia de los límites penales a su actuación. Este método de interpretación lógica, pero restrictiva, es el que garantiza la exclusión de la arbitrariedad, lo que ocurriría con interpretaciones extensivas, teleológicas o analógicas, contrarias al principio de legalidad. En tratándose de restricciones a la libertad, una interpretación restrictiva de sus límites es la única constitucionalmente válida. Ahora bien, luego de un análisis semántico de las expresiones verbales utilizadas, esta Corte concluye que no son oscuras, pero no es función de este Tribunal entrar a definirlas una a una, porque correría el riesgo de desbordar su competencia o bien respecto de la configuración de la ley o bien, respecto de la función del juez quien, en cada caso concreto, deberá interpretarlas de manera razonable, motivada en los precedentes horizontales y verticales, luego de haber sometido la interpretación al debate propio del debido proceso, que conduce a la adecuación definitiva de los hechos a las normas. En esta medida, los verbos rectores utilizados por el legislador, radican en el operador jurídico, fiscal y juez penal, un grado admisible de discrecionalidad, que no de arbitrariedad $y$, por lo tanto, satisfacen las exigencias constitucionales de tipicidad (Sentencia C-191/2016).

En cuanto al objeto de la acción, el delito de contrabando se materializa en las mercancías que sean de cuantía superior a cincuenta salarios mínimos legales mensuales que se ingresen o extraigan del territorio aduanero colombiano sin el pago de los derechos de aduana correspondientes. El precio de las mercancías se determina mediante procedimientos de valorización establecidos en el Acuerdo Relativo a la Aplicación del Artículo VII del Acuerdo General sobre Aranceles Aduaneros y Comercio de 1994.

Además, el límite de "cuantía superior a cincuenta (50) salarios mínimos legales mensuales" es considerado como parte del elemento básico 
del objeto material de este tipo penal, porque su función es delimitar aquello que es delito de lo que no lo es, permitiendo al sujeto activo orientar su actuar de acuerdo con la gravedad de la conducta y sanción correspondiente, pues si se introducen o extraen del territorio aduanero colombiano mercancías que sean de cuantía inferior a "cincuenta (50) salarios mínimos legales mensuales", la consecuencia jurídica no es la pena que se determina en el artículo 319 de la ley 599/2000 modificado por el artículo 4 de la ley 1762/2015, sino que corresponde la imposición de sanciones de carácter administrativo en concordancia con el título XV del decreto 390/2016 (Trujillo, 2007).

Por otra parte, el tipo penal del contrabando protege el bien jurídico del orden económico social (Sampedro, 2006), el cual ha sido examinado por la Corte Suprema de Justicia de la siguiente manera:

Trátase [sic] el orden económico social -sin dar por superada la controversia o dificultad en encontrar un criterio unánime para delimitar el bien que es objeto de garantía- de ser comprendido en sus dos diversas connotaciones, esto es, tanto referido a la libertad de competencia económica dentro de los límites que la dirección general de la economía que corresponde al Estado y que ejerce mediante su permanente intervención con miras a racionalizar la explotación de los recursos naturales, el uso del suelo, en la producción, distribución, utilización y consumo de los bienes y en los servicios públicos y privados, como también respecto de la actividad económica privada en concreto.

De manera tal que el orden económico social como bien plural, estaría comprendido por la protección del justo equilibrio que debe surgir entre aquellos valores de orden económico privado y aquellos que son de carácter público e interesan al Estado (fallo del 21 de julio de 2004, p19702).

Lo anterior implica que el Estado y el conglomerado social son los titulares del bien jurídico del orden económico social, pues el elemento común de resultado en el tipo penal del contrabando es de carácter físico, consistiendo en impedir que se manifieste la función extrafiscal de los derechos de aduana, en tanto estos impuestos sirven para exteriorizar la política económica del Estado, la cual representa decisiones sobre formas de intervencionismo estatal. Pero también son resultados de este delito la disminución de los ingresos del Estado y los daños para la sociedad como el aumento del desempleo, la reducción de ingresos de las empresas privadas que realizan sus actividades conforme a la ley, etc.

En cuanto a los elementos descriptivos, el tipo penal del delito de contrabando tiene un elemento de este tipo en el inciso 1 -contrabando abierto- que es "al o desde el territorio colombiano por lugares no habilitados de acuerdo con la normativa aduanera vigente", pues caracteriza la conducta en cuanto a lugar que ocurre, que no es más que en zona aduanera secundaria. Pero también, en el inciso 2 de este tipo penal -contrabando técnico- existen elementos descriptivos como "zona primaria definida en la normativa aduanera vigente" y "sin el cumplimiento de las formalidades exigidas en la regulación aduanera", en tanto el primero de estos elementos define la conducta en cuanto a lugar y el segundo la caracteriza en cuanto al modo.

Sobre los elementos normativos, el tipo penal del contrabando contiene los siguientes: (i) "mercancías": su significado se encuentra con base en el artículo 3 del decreto 390/2016, pudiéndose definir como aquellos bienes capaces de ser comercializados y transportados, cuyo ingreso y salida del territorio aduanero colombiano es grabado por el Estado con derechos de aduana, estando entonces clasificados en el decreto 4927/2011; (ii) "salarios mínimos legales mensuales": es el salario más bajo que puede pagar legalmente un empleador a su trabajador en Colombia y que es fijado anualmente por el Gobierno nacional, para el año 2017 el decreto 2209/2016 estableció el salario mínimo mensual en 737.717 pesos colombianos; (iii) "territorio colombiano": se refiere al territorio aduanero colombiano, cuyo 
significado se basa en el artículo 3 del decreto 390/2016, definiéndose como el aspecto espacial que implica la vigencia de la legislación aduanera colombiana y el traspaso de su demarcación con mercancías da origen a los derechos de aduana; (iv) "lugares no habilitados de acuerdo con la normativa aduanera vigente": igualmente su significado se apoya en el artículo 3 del decreto 390/2016, definiéndose en este la zona primaria aduanera como el lugar del territorio aduanero colombiano habilitado por la autoridad aduanera para la realización de operaciones materiales de recepción, almacenamiento y movilización de mercancías que entran o salen del país, en donde la aduana ejerce en concordancia con las normas tributarias y aduaneras su función de control y vigilancia, pero además el mismo artículo define zona secundaria aduanera como la parte del territorio aduanero colombiano que no es zona primaria aduanera, es decir, aquel lugar que no está habilitado para la introducción y extracción de mercancías del territorio aduanero colombiano; y (v) "valor aduanero de los bienes objeto del delito": es el precio de las mercancías sobre las que se materializa el delito de contrabando, el cual es determinado mediante procedimientos de valorización establecidos en el Acuerdo Relativo a la Aplicación del Artículo VII del Acuerdo General sobre Aranceles Aduaneros y Comercio de 1994. La Corte Constitucional expresa sobre este último elemento normativo que:

La aplicación del valor en aduanas o valor aduanero para establecer el monto mínimo constitutivo de delito se refiere entonces a la tipicidad del delito, mientras que su utilización como patrón de la multa, se refiere a la legalidad de las penas (Sentencia C-191/2016).

Otros elementos normativos del tipo penal del contrabando son: (vi) "zona primaria definida en la normativa aduanera vigente": su significado se soporta en el artículo 3 del decreto 390/2016, entendiéndola como zona primaria aduanera; (vii) "cumplimiento de las formalidades exigidas en la regulación aduanera": alude a los requisitos para la importación y exportación que ordena el decreto 390/2016 y demás normas aduaneras que lo complementen; (viii) "Usuario Altamente Exportador (Altex)": es una calidad otorgada por la Dirección de Impuestos y Aduanas Nacionales a las personas por reunir los requisitos fijados en el artículo 36 del decreto 2685/1999, otorgándoles los beneficios que aparecen en el artículo $39 \mathrm{del}$ mismo decreto para realizar sus actividades de exportación; (ix) "Usuario Aduanero Permanente (UAP)": es una calidad concedida por la Dirección de Impuestos y Aduanas Nacionales a las personas por reunir los requisitos establecidos en el artículo 28 del decreto 2685/1999, otorgándoles beneficios instituidos en el artículo 33 del mismo decreto para sus actividades aduaneras, (x) "Usuario u Operador de Confianza": es una calidad reconocida por el numeral 2 del artículo 34 del decreto 390/2016, la cual confiere la Dirección de Impuestos y Aduanas Nacionales a las personas, dándoles los beneficios creados en el artículo 35 del mismo decreto; (xi) "Operador Económico Autorizado (OEA)": es una calidad reconocida por el numeral 1.2. del artículo 34 del decreto 390/2016 y que regula el decreto 3568/2011, la cual es otorgada por la Dirección de Impuestos y Aduanas Nacionales a las personas, proporcionándoles los beneficios que se consignan en el artículo 8 del decreto 3568/2011; (xii) "cualquier operador con un régimen especial de acuerdo con la normativa aduanera vigente": es un término general que engloba cuanta calidad aduanera especial exista o pueda crearse luego de la expedición de la ley 1762/2015, a través de decretos emitidos por el presidente de la República y reglamentados por resoluciones de la Dirección de Impuestos y Aduanas Nacionales.

Sobre las figuras de Altex y UAP, el numeral 1 del artículo 675 del decreto 390/2016 les da la posibilidad de operar por cuatro años más a partir de la entrada en vigencia de ese decreto, es decir que, "los usuarios aduaneros permanentes y altamente exportadores se descalificarán el 22 de marzo de 2020, por lo que es necesario migrar a alguna de las figuras y no perder de vista la competitividad como objetivo de esta nueva regulación" (Cano, 2016, p. 13). 
Se debe señalar igualmente sobre la figura de Altex, que el literal b del artículo 39 del decreto 2685/1999 le otorga como beneficio la "Eliminación de la inspección física aduanera, sin perjuicio de que la autoridad aduanera pueda realizarla de manera aleatoria o selectiva cuando lo considere conveniente", flexibilizándose con ello las normas sobre importación y exportación respecto a esa obligación que tienen las personas de someter a control e inspección las mercancías a las autoridades aduaneras. Es por eso que si se desea determinar la tipificación del delito de contrabando en un caso específico que involucra un Altex, se debe tener en cuenta que esta figura por aspectos circunstanciales puede tener la excepción de la inspección por la autoridad aduanera, lo que no significa que este sujeto especial de derecho aduanero tenga permitido la comisión de contrabando.

Similar a lo anterior sucede con la figura del OEA, pues los numerales 5 y 6 del artículo 8 del decreto 3568/2011 le otorga los siguientes beneficios:

5. Disminución del número de reconocimientos, inspecciones físicas y documentales para las operaciones de exportación, importación y tránsito aduanero por parte de la Dirección de Impuestos y Aduanas Nacionales y, disminución de inspecciones físicas para las operaciones de exportación por parte de la Dirección de Antinarcóticos de la Policía Nacional.

6. Utilización de procedimientos especiales y simplificados para el desarrollo de las diligencias de reconocimiento o de inspección, según sea el caso, cuando estas se determinen como resultado de los sistemas de análisis de riesgos por parte de las autoridades de control.

Por otra parte, hay elementos aleatorios de circunstancias agravantes de la responsabilidad en el tipo penal del contrabando en los incisos 3 y 4: (i) la primera circunstancia agravante es de carácter específico y se establece en el inciso 3 , que hace uso de un límite cuantitativo, pues si el contrabando recae "sobre mercancías en cuantía superior a doscientos (200) salarios mínimos legales mensuales" la pena privativa de la libertad ya no será de "cuatro (4) a ocho (8) años" como se indica en el inciso 1 de este artículo, sino que la pena a imponer corresponderá "de nueve (9) a doce (12) años de prisión", implicando que entre mayor sea la cuantía de las mercancías objeto de contrabando mayor será la lesión al bien jurídico del orden económico social; (ii) en el inciso 4 hay una circunstancia agravante consistente en que el sujeto activo de la conducta sea "Usuario Altamente Exportador (Altex), de un Usuario Aduanero Permanente (UAP), o de un Usuario u Operador de Confianza, de un Operador Económico Autorizado (OEA) o de cualquier operador con un régimen especial de acuerdo con la normativa aduanera vigente", agravándose la pena en razón a que la comisión del delito de contrabando se realiza con abuso de los beneficios otorgados por la Dirección de Impuestos y Aduanas Nacionales con previo cumplimiento de los requisitos legales, beneficios que tienen como fin la facilitación de las actividades comerciales aduaneras; y (iii) la última circunstancia de agravación punitiva del tipo penal del contrabando se encuentra igualmente en el inciso 4 del artículo 319 de la ley 599/2000 modificado por el artículo 4 de la ley $1762 / 2015$, la cual consiste en la reincidencia del sujeto activo del delito.

\section{Conclusiones}

El contrabando es un delito que consiste en la introducción y extracción del territorio aduanero nacional de mercancías sin el pago de los derechos de aduana, siendo tipificado por el artículo 319 de la ley 599/2000 modificado por el artículo 4 de la ley 1762/2015, conteniendo su tipo penal elementos que para su comprensión $e$ interpretación requieren necesariamente del entendimiento de conceptos que se encuentran en normas del derecho de la hacienda pública, el derecho tributario y el derecho aduanero, en razón a la relación constitutiva del delito de contrabando con aquellos conceptos y por ser un tipo penal en blanco. 
No obstante, la existencia de zonas de régimen especial aduanero genera una flexibilización de las normas jurídicas sobre importación y exportación, pues con aquellas zonas lo que se busca es dar estímulo al desarrollo en esas partes del Estado colombiano mediante la concesión de beneficios al comercio; por lo que cuando en un caso concreto se desee saber si se tipifica contrabando e involucra una de estas zonas, se debe tener en cuenta los títulos XII y XIII del decreto 390/2016 para determinarlo.

También la flexibilización de las normas sobre importación y exportación ocurre en relación con esa obligación que tienen las personas de permitir el control e inspección de las autoridades aduaneras sobre las mercancías, cuando se trata de los sujetos especiales de derecho aduanero de Altex y OEA, pues estas figuras tienen el beneficio de eliminación o disminución del número de reconocimientos, inspecciones físicas y documentales por las autoridades aduaneras, según el literal b del artículo 39 del decreto 2685/1999 y los numerales 5 y 6 del artículo 8 del decreto 3568/2011. Lo que no connota que estén autorizados estos sujetos especiales del derecho aduanero para cometer contrabando, siendo incluso agravada la pena cuando se realiza este delito en el abuso de sus beneficios concedidos por la Dirección de Impuestos y Aduanas Nacionales al cumplirse previamente con los requisitos para esas figuras.

Finalmente, el delito de contrabando en su tipo penal tiene circunstancias de agravación punitiva y entre ellas la reincidencia, la cual se encuentra establecida de forma singular, pues en el sistema jurídico colombiano solo está tipificada para la pena de prisión en el artículo 319 de la ley 599/2000 modificado por el artículo 4 de la ley 1762/2015.

\section{Referencias}

Amatucci, A. \& González, E. (2001). El concepto de tributo. En: A. Amatucci, E. González \& C. Trzaskalik (eds.). Tratado de derecho tributario. La relación jurídico-tributaria del procedimiento de la aplicación de la norma tributaria. Tomo II. (pp. 3-16). Bogotá: Temis.

Asamblea Nacional Constituyente. (1991). Constitución Política de Colombia. Bogotá: Asamblea Nacional Constituyente.

Cano, J. (2016). La nueva regulación aduanera: ¿solución a los problemas del comercio exterior colombiano? Revista de Derecho Fiscal, 8, 29-42. Disponible en: http://revistas.uexternado.edu.co/index.php/fiscal/ article/view/4749

Carantón, M. (2016). Incentivos que promueven el contrabando técnico en Colombia. Tesis de especialización en Gerencia de Comercio Internacional. Bogotá: Universidad Militar Nueva Granada. Disponible en: http://repository.unimilitar.edu.co/handle/10654/15447

Carrara, F. (1982). Programa de derecho criminal. Parte especial. Vol. II. (4a ed.). Bogotá: Temis.

Chávez, J. (2000). Para recobrar la confianza en el gobierno hacia la transparencia y mejores resultados con el presupuesto público. Ciudad de México: Fondo de Cultura Económica.

Corte Constitucional de Colombia. (1992). Sentencia C-510. M. P.: Eduardo Cifuentes Muñoz.

Corte Constitucional de Colombia. (1992). Sentencia T-533. M. P.: Eduardo Cifuentes Muñoz.

Corte Constitucional de Colombia. (1993). Sentencia C-040. M. P.: Ciro Angarita Barón.

Corte Constitucional de Colombia. (1998). Sentencia SU-747. M. P.: Eduardo Cifuentes Muñoz.

Corte Constitucional de Colombia. (2001). Sentencia C-121. M. P.: Jairo Alberto Corzo.

Corte Constitucional de Colombia. (2012). Sentencia C-121. M. P.: Luis Ernesto Vargas.

Corte Constitucional de Colombia. (2016). Sentencia C-191. M. P.: Alejandro Linares. 
Corte Constitucional de Colombia. (2016). Sentencia C-203. M. P.: Alberto Rojas.

Corte Suprema de Justicia de Colombia. (2004). Sala de Casación Penal. Proceso 19702. M. P.: Alfredo Gómez Quintero.

Dirección de Impuestos y Aduanas Nacionales \& Unidad de Información y Análisis Financiero. (2006). Tipologías de lavado de activos relacionadas con contrabando. Disponible en: http://www.legiscomex.com/ bancomedios/archivos/tipologias_contrabando_enero_2006.pdf

Fernández, J. (1989). Derecho penal fundamental, teoría general del delito y punibilidad. Vol. II. (2 $2^{\text {a }}$ d.). Bogotá: Temis.

Ferreira, F. (2006). Derecho penal especial. Tomo II. Bogotá: Temis.

Ferreiro, J. (2001). Elementos constitutivos de la obligación tributaria. En: A. Amatucci, E. González \& C. Trzaskalik (eds.). Tratado de derecho tributario. La relación jurídico-tributaria del procedimiento de la aplicación de la norma tributaria. Tomo II. (pp. 44-60). Bogotá: Temis.

García, H. \& Ortega, A. (2004). Hacienda pública ( $2^{\mathrm{a}}$ ed.). Bogotá: Ecoe editores.

Gómez, J. (2005). Tratado de derecho penal parte general, la tipicidad. Tomo III. Bogotá: Ediciones Doctrina y Ley.

Indriago, J. (1976). El delito de contrabando legislación penal fiscal. Bogotá: Temis.

Ley 7 de 1991. Por la cual se dictan normas generales a las cuales debe sujetarse el Gobierno Nacional para regular el comercio exterior del país, se crea el Ministerio de Comercio Exterior, se determina la composición y funciones del Consejo Superior de Comercio Exterior, se crean el Banco de Comercio Exterior y el Fondo de Modernización Económica, se confieren unas autorizaciones y se dictan otras disposiciones. Diario Oficial 39632.
Ley 170 de 1994. Por medio de la cual se aprueba el Acuerdo por el que se establece la "Organización Mundial de Comercio (OMC)", suscrito en Marrakech (Marruecos) el 15 de abril de 1994, sus acuerdos multilaterales anexos y el Acuerdo Plurilateral anexo sobre la Carne de Bovino. Diario Oficial 41637.

Ley 599 de 2000. Por la cual se expide el Código Penal. Diario Oficial 44.097.

Ley 1609 de 2013. Por la cual se dictan normas generales a las cuales debe sujetarse el Gobierno para modificar los aranceles, tarifas y demás disposiciones concernientes al Régimen de Aduanas. Diario Oficial 48661.

Ley 1709 de 2014. Por medio de la cual se reforman algunos artículos de la Ley 65 de 1993, de la Ley 599 de 2000, de la Ley 55 de 1985 y se dictan otras disposiciones. Diario Oficial 49039.

Ley 1762 de 2015. Por medio de la cual se adoptan instrumentos para prevenir, controlar y sancionar el contrabando, el lavado de activos y la evasión fiscal. Diario Oficial 49565.

López, J. (2014). La nueva ley marco de aduanas -Ley 1609 de 2013- análisis y cambios normativos frente a la regulación y tributación aduanera en Colombia. Tesis de especialización en Derecho Tributario. Bogotá: Pontificia Universidad Javeriana. Disponible en: https://repository.javeriana. edu.co/handle/10554/14928

Muñoz, K. (2015). Impacto de la ley anticontrabando 1762 de 2015 en instituciones como la DIAN, la UIAF, la policía fiscal y aduanera y la comisión interinstitucional en su lucha contra el contrabando en Colombia. Tesis de pregrado de Relaciones Internacionales y Estudios Políticos. Bogotá: Universidad Militar Nueva Granada. Disponible en: http://repository.unimilitar.edu.co/bitstream/10654/15319/5/ Mu\%C3\%B1oz\%20Clavijo\%20Karen\%20 Steffany\%20A\%C3\%B1o\%202016.pdf 
Naranjo, A. \& Zapata, D. (2012). Zonas de régimen aduanero especial. Tesis de especialización en Políticas y Legislación Tributaria. Medellín: Universidad de Medellín. Disponible en: http://repository.udem.edu. co/bitstream/handle/11407/369/Zonas\%20 de\%20r\%C3\%A9gimen\%20aduanero\%20 especial.pdf?sequence $=1$

Pardo, G. (2009). Tributación aduanera. Bogotá: Legis.

Plazas, M. (2005). Derecho de la hacienda pública y derecho tributario. Tomo II. Derecho tributario (2a ed.). Bogotá: Temis.

Presidencia de la República. (2011). Decreto 4927 "Por el cual se adopta el Arancel de Aduanas y otras disposiciones". Diario Oficial 48.297. Bogotá: Imprenta Nacional.

Presidencia de la República. (2016). Decreto 390 "Por el cual se establece la regulación aduanera". Diario Oficial 49808. Bogotá: Imprenta Nacional.

Ramírez, A. (1998). Hacienda pública (4ª ed.). Bogotá: Temis.
Russo, P. (2001). Obligación tributaria. En: A. Amatucci, E. González \& C. Trzaskalik (eds.). Tratado de derecho tributario. $\mathrm{La}$ relación jurídico-tributaria del procedimiento de la aplicación de la norma tributaria. Tomo II. (pp. 17-43). Bogotá: Temis.

Sampedro, C. (2006). Delitos aduaneros. En: Lecciones de derecho penal (pp. 711744). Bogotá: Universidad Externado de Colombia.

Trujillo, C. (2007). Los límites cuantitativos en los delitos económicos (arts. 297, 319, 320, 321 Código Penal colombiano). Tesis de pregrado. Medellín: Universidad Eafit. Disponible en: https://repository.eafit.edu. co/bitstream/handle/10784/461/Catalina TrujilloBetancur_2007.pdf?sequence $=1$

Velásquez, F. (2004). Manual de derecho penal ( $2^{\text {a }}$ ed.). Bogotá: Temis.

Welzel, H. (1956). Derecho penal parte general. Buenos Aires: Roque Depalma Editor.

Welzel, H. (2004). El nuevo sistema del derecho penal. Buenos Aires: B de F. 